\title{
Heritability Estimates of Karen Horney's Core Neurotic Trends in a Young Adult Twin Sample
}

\author{
Frederick L. Coolidge ${ }^{1}$, Daniel L. Segal1 ${ }^{1}$, Alisa J. Estey¹, Frank M. Spinath², Elisabeth Hahn², \\ Juliana Gottschling ${ }^{2}$ \\ ${ }^{1}$ University of Colorado, Colorado Springs, CO, USA \\ ${ }^{2}$ Saarland University, Saarbrücken, Germany \\ Email: fcoolidg@uccs.edu
}

Received 23 October 2015; accepted 22 December 2015; published 25 December 2015

Copyright $@ 2015$ by authors and Scientific Research Publishing Inc.

This work is licensed under the Creative Commons Attribution International License (CC BY).

http://creativecommons.org/licenses/by/4.0/

(c) (i) Open Access

\begin{abstract}
Objective: The purpose of the present study was to explore the heritability of psychoanalyst Karen Horney's three core neurotic trends (i.e., compliance, aggression, and detachment) in a twin paradigm to evaluate the validity of her theoretically assumed origins of neuroses. Method: Data were collected from 168 adult participants $(M$ age $=21.54$ years; range $=18-25$ years $)$ including 60 monozygotic twin pairs (10 male pairs and 50 female pairs) and 24 dizygotic twin pairs (4 male pairs and 20 female pairs). Participants completed the 57-item Horney-Coolidge Tridimensional Inventory (HCTI). Results: The best fitting model for compliance and detachment included additive genetic and nonshared environmental influences. For aggression, phenotypic variance was completely traced back to shared and nonshared environmental influences. Conclusions: The results are discussed in light of Horney's hypotheses for the genesis of neurotic trends as well as findings from behavioral genetic research.
\end{abstract}

\section{Keywords}

Horney-Coolidge Tridimensional Inventory (HCTI), Heritability, Karen Horney, Twin Study, Core Neurotic Trends

\section{Introduction}

In her interpersonal theory, psychoanalyst Karen Horney $(1945,1950)$ postulates that the difference between a

\footnotetext{
*Corresponding author.
}

How to cite this paper: Coolidge, F. L., Segal, D. L., Estey, A. J., Spinath, F. M., Hahn, E., \& Gottschling, J. (2015). Heritability Estimates of Karen Horney's Core Neurotic Trends in a Young Adult Twin Sample. Psychology, 6, 2013-2024. 
healthy and a neurotic personality can be traced back to the quality of interpersonal relationships, in particular to the early interaction between parent and child. She suggested that parental indifference, that is, a lack of warmth and affection toward a child (e.g., preferring one child of the family, unjustified accusations, unfulfilled promises, switching between neglect and overindulgence) may cause a feeling of isolation and helplessness leading in turn to a "basic anxiety". As a reaction to this experienced inconsistent parental behavior, Horney theorized that a child would strive for ways or strategies to cope. Horney proposed that these coping mechanisms were not ad hoc ego defenses but that they could become chronic personality characteristics, which she labeled "neurotic trends". Unlike other theorists of the time, Horney assumed them to be continuous with the normal life course rather than being a categorical, behavioral trend. Thus, she assumed that neurotic trends were observable in all people and represented their coping attempts to maintain interpersonal control. Horney postulated three main and relatively independent defense mechanisms, which enabled a child to deal with external stressors: a child could move toward people (known as the compliant type), against people (known as the aggressive type) or away from people (known as the detached type).

According to Horney (1945), the compliant type has a strong need for affection and approval from others and especially a need for a "partner". The neurotic aspects of the compliant type include compulsivity, indiscriminate tendencies for moving towards other people, and anxiety or depression when frustrated. Just as the compliant type indiscriminately perceives all people to be nice (often to their chagrin), the aggressive type assumes that others are hostile and that life is a constant struggle. Fear is never admitted or shown and they attempt to exclude feelings altogether. There is a strong need to outsmart or exploit others and relationships are developed solely to better themselves. Their primary need is having control of others and life is seen as a battle they must fight to win. For the detached type, Horney emphasized that it is not merely a person who wants to occasionally be alone, as she noted that nearly everyone wants to be alone at certain times. For Horney, the detached type contains an estrangement even from one's own self, including the numbness to emotional experiences and a strong amount of uncertainty as to one's feelings, including love, hate, desires, beliefs, etc. However, she did note that some detached types may have rich emotional lives as she proposed that all detached types have a capacity to look at themselves and others with an "objective interest" in common. This description of the three core neurotic trends clearly illustrates the presumption of their continuity over the life course and those types may represent extreme forms of normal behavior.

Paris (1994) claimed that Horney's concept of neuroses could be best typified as personality disorders in the modern diagnostic terminology of the Diagnostic and Statistical Manual of Mental Disorders (DSM-III; American Psychiatric Association, 1987). By using an operationalization of Horney's three interpersonal styles (i.e., the Horney-Coolidge Tridimensional Inventory [HCTI]; Coolidge, 1998; Coolidge, Moor, Yamazaki, Stewart, \& Segal, 2001; Coolidge, Segal, Benight, \& Danielian, 2004; Coolidge, Segal, Estey, \& Neuzil, 2011), this suspected relationship between Horney's types of neuroses and personality disorders was confirmed in two independent samples. Each of the three styles showed a significant relation to at least one personality disorder. For instance, the strongest relation for compliance was found with antisocial $(r=-.44)$ and histrionic $(r=.33)$ personality disorders, whereas aggression showed the strongest relation with sadistic $(r=.55)$ and antisocial personality disorder $(r=.50)$. Finally, detachment was most strongly associated with schizoid $(r=.64)$ and schizotypal $(r=.53)$ personality disorder (Coolidge et al., 2001). In 2004, Coolidge et al. further examined the three HCTI dimensions as a function of the three DSM-IV-TR personality disorder clusters: odd or eccentric (Cluster A); dramatic, emotional, or erratic (Cluster B); and anxious or fearful (Cluster C). By means of multiple regression, the results showed that detachment $(\beta=.41, p=.001)$ and aggression $(\beta=.29, p=.001)$ best predicted Cluster $\mathrm{A}$, aggression $(\beta=.57, p=.001)$ best predicted Cluster $\mathrm{B}$, and detachment $(\beta=.31, p=.001)$ and compliance $(\beta=.30, p=.001)$ best predicted Cluster C.

To further understand Horney's psychoanalytic theory, it is also of crucial importance to address the question about the proposed origins of neurotic trends. Contrary to Freud, who emphasized that the driving forces in neuroses were largely instinctual in their nature (Freud, 1913/2010), Horney (1945) did not note any instinctual drives or genetic influences on the three neurotic trends in her early work. For Horney, each individual strives to attain self-realization and if external stressors (e.g., cultural pressures, parental indifference) challenge the process of self-realization, neurosis may arise. The development of a neurotic trend is therefore assumed to be a consequence of a child's early interpersonal relationship within the nuclear family: if a child experiences parental indifference it initially responds with a "basic hostility". If this behavior is successful in terms of receiving attention or affection, the child is likely to develop an aggressive coping style. If the child mainly experiences a "basic anxiety" of helplessness and abandonment, this may lead to compliance as a coping strategy. Finally, if 
children learn from their early interpersonal interactions that they can resolve stressful situations by retreating, they will withdraw from social situations and develop a detached coping style. In her later work, however, Horney (1950) expanded upon the intrapsychic mechanisms underlying the three interpersonal strategies as she supposed the real self to have "intrinsic potentialities" and "particular human potentialities" (p. 17), which Paris (1999) and others (Grigorenko, 2011) have interpreted as the equivalent of genetic predispositions. However, she always maintained her original position that neuroses were created largely by cultural factors in early childhood experiences and that actual neuroses were largely created by pathogenic conditions in the family environment.

This latter assumption, though, contrasts with the empirical evidence derived from quantitative genetic studies showing that almost all complex human traits and behaviors have an underlying genetic predisposition (Johnson, Turkheimer, Gottesman, \& Bouchard, 2009; Turkheimer, 2000; Polderman et al., 2015). If Horney’s use of the phrases "intrinsic potentialities" and "particular human potentialities" were meant to imply unambiguously there were some genetically driven behaviors, then her claims of the strong influence of cultural factors are not at odds with current genetic findings about human behavior. Contemporary quantitative genetic methods (e.g., twin and adoption studies) are designed to disentangle the genetic and environmental origins of interindividual differences in human traits in order to explain why particular personality characteristics appear across generations in families. Twin studies can therefore be used to test various predictions about the roots of neurotic trends. It is also important to note that within behavioral genetics, a distinction is made between the shared and the nonshared environment. While the former refers to the environment common to both members of a twin pair and is therefore assumed to contribute to similarity between family members, the latter results from environmental effects that are specific for each individual and therefore contribute to dissimilarity. Thus, with respect to Horney's theory, her understanding of the environment was on a family-by-family basis, that is, she assumed shared environmental influences to be the major cause of neuroses.

As no previous study to date has explored the genetics of Horney's neurotic trends, assumptions about the genetic and environmental origins of interindividual differences in these dimensions can be derived from behavior genetic studies on personality disorders as well as other coping strategies (i.e., cognitive or behavioral responses to stressors). Knowledge about the heritability of the personality trait neuroticism (typically characterized by self-centeredness, irritability, anger, depression, anxiety, worry, hostility, high levels of self-criticism and criticism of others, and feelings of inadequacy and vulnerability; e.g., McCrae \& Costa, 1999; Watson, Clark, \& Harkness, 1994) can also provide insight into the underlying mechanisms of interindividual differences in core neurotic trends, given their conceptual proximity.

With respect to personality disorders, numerous genetically sensitive studies implicate a high heritability of the complete range of personality disorders as well as their largely overlapping genetic basis (for an overview see Livesley \& Jang, 2008; Polderman et al., 2015). Depending on the methods of ascertainment (e.g., structured interviews, self-reports), the sample used (clinical vs. non-clinical), and the behavior genetic research design (e.g., twin studies or family studies), heritability estimates for adults are typically in the range of $21 \%$ to $60 \%$ for Cluster A (paranoid, schizoid, and schizotypal personality disorders), $25 \%$ to $77 \%$ for Cluster B (antisocial, borderline, histrionic, and narcissistic personality disorders), and $27 \%$ to $77 \%$ for Cluster C (avoidant, dependent, and obsessive-compulsive personality disorders) (see reviews by Reichborn-Kjennerud, 2010; Torgersen, 2009). In a study with young twins (between ages 4 and 15 years old) rated by their parents, the heritability estimates were even higher, varying between $81 \%$ for schizotypal and dependent personality disorders and $50 \%$ for paranoid and passive-aggressive personality disorders (Coolidge, Thede, \& Jang, 2001). However, independent of the age, the sample characteristics, and the estimation method used, nonshared environmental influences accounted for the remaining variance in personality disorders, whereas shared environmental influences were not significant with the exception of antisocial behavior (Livesley \& Jang, 2008). Contrary to what would have been expected based on Horney's interpersonal theory, the implication that the significance of the environment is nonshared rather than shared, is common in behavior genetic studies. Furthermore, this could also hold for influences that are classically assumed to be shared between children growing up in the same family, such as parental treatment (see Plomin, 2011). Additionally, the genetic influences underlying personality disorders are additive (each gene contributes independently) rather than nonadditive (combination of genes).

Recent studies have also explored the etiologic contributions of different coping styles, such as problem oriented or emotional oriented responses to stressors. Although they are often considered to be a product of learning and experience (e.g., Heszen-Niejodek, 1997), studies examining the genetic and environmental origins of coping styles concurrently report genetic influences explaining between $30 \%$ and $50 \%$ of the phenotypic variance (Busjahn, Faulhaber, Freier, \& Luft, 1999; Jang, Thordarson, Stein, Cohan, \& Taylor, 2007; Kendler, 
Kessler, Heath, Neale, \& Eaves, 1991; Kozak, Strelau, \& Miles, 2005).

Behavioral genetic research has also identified genetic factors for the trait of neuroticism. In their meta-analytic review encompassing results derived from various research designs (i.e., twin studies, adoption studies, and combination designs), Johnson, Vernon and Feiler (2008) reported a broad heritability (i.e., additive and nonadditive genetic variance combined) of $41 \%$ for neuroticism, whereas shared environmental influences were found to be negligible.

It should also be noted that the classical twin design is supposed to have a lack of statistical power to detect nonadditive genetic as well as shared environmental influences (Neale, Eaves, \& Kendler, 1994; Visscher, Gordon, \& Neale, 2008). However, the lack of small and/or nonsignificant nonadditive or shared environmental effects in the classical twin design does not necessarily imply that they do not exist.

As described previously, behavioral genetic methods are suitable to disentangle the genetic and environmental influences on interindividual differences in complex human traits, such as neurotic trends. In this way it can also be tested whether Horney's $(1945,1950)$ theoretical assumptions about the major cause of neurotic trends, i.e., not genetically predisposed but rather driven by shared environmental influences, can be supported.

Using a young adult twin sample, the current study attempts to estimate the relative contributions of genetic and environmental factors in interindividual differences in Horney's three neurotic trends, as operationalized by Coolidge (1998) in his HCTI. Based on the results of behavioral genetic studies on personality disorders, coping styles and neuroticism, it is hypothesized that genetic factors should account for much of the observed phenotypic variation in these dimensions, whereas the influence of the environment should mainly be nonshared. The hypothesis will be tested by means of structural equation modeling, which provides a statistical approach to disentangle the sources of variation in human traits.

\section{Method}

\subsection{Participants and Procedures}

The present sample was obtained from a larger twin registry at the Institute for Behavioral Genetics (IBG), Boulder, Colorado. From that registry, a sample of young adults were contacted by mail and asked to volunteer for the study pro bono, as the main measure used in the present study typically requires only 15 minutes to complete. Only same-sex twins were included in the sample. Data were collected from 168 adult participants, 60 monozygotic (MZ) twin pairs (10 male pairs and 50 female pairs) and 24 dizygotic (DZ) twin pairs (4 male pairs and 20 female pairs). They ranged in age from 18 years old to 25 years old $(M=21.54 ; S D=2.23$ years). The twins returned their protocols by mail to a senior staff member at IBG. The procedures, protocol, and informed consent in the present study met the ethical standards of and were approved by the University of Colorado Research Committee in Boulder, Colorado and by the Institutional Review Board of the University of Colorado, Colorado Springs, Colorado.

\subsection{Zygosity Assessment}

Zygosity was determined by a combination of researchers ratings and DNA genotyping. First, the researchers' ratings were made for each twin pair on a 9-item measure of physical similarities and differences (Nichols \& Bilbro, 1966), which has been empirically demonstrated to be sufficiently valid to make determinations of zygosity. Next, DNA cheek swabs were obtained and genotyped at a minimum of 11 informative short tandem repeat polymorphisms (STRPs), using a standard polymerase chain reaction method and ABI 377 genotyping technology. Any twins with discrepancies between the ratings and DNA calls were evaluated by a staff member of the IBG for regenotyping (see Rhea, Gross, Haberstick, \& Corley, 2006, for further information). These zygosity determinations were made prior to the present study.

\subsection{Measures}

The HCTI (Coolidge, 1998; Coolidge et al., 2001; Coolidge et al., 2004; Coolidge et al., 2011) is a 57-item self-report inventory, which measures the three interrelationship dimensions of compliance, aggression and detachment, as described in Horney's book, Our Inner Conflicts (Horney, 1945). Participants answer the items on a 4-point Likert-type scale ranging from 1 (hardly ever) to 4 (nearly always). The three HCTI dimensions are made up of three facets each (determined through principal components analysis; see Coolidge et al., 2001). The Compliance scale consists of altruism (items related to an altruistic nature, desire to help others, sympathy, and 
unselfishness), need for relationships (a strong need to be in a relationship and the desire for others), and self-abasement (the subjugation of one's own needs to another). For the Aggression scale, the three facets are malevolence (a malevolent view of others, their motivations, and the world), power (desire to be in command and outsmarting others), and strength (values related to bravery, uninhibited behavior, and toughness). The facets of the Detachment scale are the need for aloneness (preference for being alone and feeling better when alone), avoidance (avoidance and resistance of personal interactions), and self-sufficiency (enjoyment of living independent of family and friends).

The internal scale reliabilities (Cronbach's alpha) obtained on the normative sample ( $N=630$ purportedly normal adults, 15 to 90 years, 315 men and 315 women; Coolidge, 1998) for the three main scales were Compliance, $\alpha=.78$, Aggression, $\alpha=.83$, and Detachment, $\alpha=.82$. The test-retest reliabilities measured using a 1week interval were: Compliance, $r_{t t}=.92$, Aggression, $r_{t t}=.92$, and Detachment, $r_{t t}=.91(N=67)$. The subsequent analyses were based on scale scores of the three dimensions of the HCTI (and not the facets).

\subsection{Statistical Analyses}

Prior to genetic modeling, analysis of variances (ANOVAs) were performed on the three main scales to test for main effects of sex and age, as well as their interaction. The main effect of sex was significant for Compliance $(F=4.57 ; p<.05)$ and Detachment $(F=5.76 ; p<.05)$. Women scored higher on the Compliance scale, whereas men had higher scores on the Detachment scale. There was also a significant age effect found for the Compliance scale $(F=4.36 ; p<.01)$. In order to avoid an overestimation of shared environmental influences (McGue \& Bouchard, 1984) and as testing sex and age differences were beyond the power of the present study's sample size, all variables were regressed on sex and age by applying the regression technique described by McGue and Bouchard.

\subsection{Quantitative Genetic Analyses}

The behavioral genetic analyses were based on the general assumptions of the classical twin design (CTD; for a summary of the twin method, see Neale \& Maes, 2004; Plomin, DeFries, McClearn, \& McGuffin, 2008; Rijsdijk \& Sham, 2002). The CTD allows to separate the observed variance of a phenotype into genetic (additive and nonadditive genetic influences) and environmental (shared and nonshared environmental influences) components. Additive genetic influences (A) encompass all allelic effects within and across genes, while nonadditive genetic influences (D) refer to the effects of alleles (dominance) or loci (epistasis) that interact with other alleles or loci (Plomin et al., 2008). Shared environmental influences (C) are common to each member of a twin pair and are therefore assumed to contribute to similarity between family members. Nonshared environmental influences (E) result from environmental effects that are specific for each individual and therefore contribute to dissimilarity.

Within the CTD (see Figure 1), the different degree of genetic relatedness between MZ twin pairs (who are

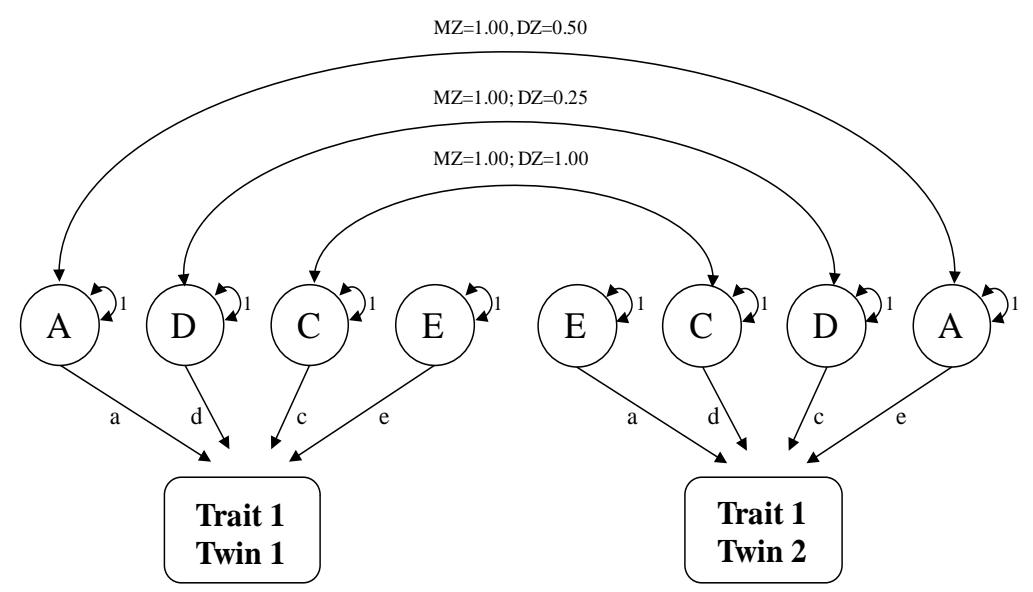

Figure 1. Univariate classical twin design model. A= additive genetic effects, $\mathrm{D}=$ non-additive genetic effects, $\mathrm{C}=$ shared environmental effects, $\mathrm{E}=$ nonshared environmental effects, $\mathrm{MZ}=$ Monozygotic twin pairs, $\mathrm{DZ}=$ Dizygotic twin pairs. 
genetically identical), and DZ twin pairs (who share, on average, 50\% of their segregating genes), is used to estimate the contribution of genetic and environmental factors to interindividual differences in the trait being investigated. Therefore, the A and D correlation is 1.00 for MZ pairs, whereas for DZ pairs, the A correlation equals .50 and the D correlation equals .25. C influences are assumed to contribute equally to the resemblance in $\mathrm{MZ}$ and $\mathrm{DZ}$ pairs, so shared environmental correlation equals 1.00 for both zygosity groups. Because $\mathrm{C}$ and $\mathrm{D}$ are confounded in the CTD, they cannot be estimated simultaneously (Ozaki, Toyoda, Iwama, Kubo, \& Ando, 2001). Finally, there is no correlation for $\mathrm{E}$ by definition for both groups. The E component is modeled as residual variance. This parameter also includes variance that is attributable to random error of measurement (Neale \& Maes, 2004). A first indication of the relative impact of genetic and environmental influences, as well as whether $\mathrm{C}$ or $\mathrm{D}$ are expected in a particular model, can be obtained by inspecting the twin similarities, which are typically calculated as intraclass correlations (ICC; Shrout \& Fleiss, 1979). The ICC is thought to be the more appropriate measure of twin similarity compared to Pearson's $r$ because it partitions the total variance into within pair and between pair components (Neale \& Maes, 2004). Higher MZ than DZ trait correlations are, in general, an indicator of genetic influences on the trait under study, because of the larger genetic similarity of MZ twins. If MZ correlations are more than twice the size of the DZ correlation, A influences are implied and variance is expected. C influences are supposed to be of relevance, if MZ and DZ twins show a high and comparable similarity since these influences act on MZs and DZs in the same way, resulting in an increased similarity of both siblings. Because MZ twins are genetically identical (including A and D influences), less than perfect MZ twin correlations $\left(r_{M Z}<1\right)$ suggest E influences.

Structural equation modeling on raw data (corrected for the linear effect of age and sex) was applied to estimate the relative contributions of genetic and environmental influences on the HCTI scales, using the Mx Software package (Neale, Boker, Xie, \& Maes, 2003). Due to the limited sample size, nested models (AE, CE, DE, or E model) were not tested, because it is more likely to accept the false model based on the criterion of parsimony when effects of sampling are large (Sullivan \& Eaves, 2002). Sullivan and Eaves (2002) also stated that the exclusion of A, C (D), or E may result in biased estimates of the remaining factors, even if the removed factor was not significant. Therefore, we solely concentrated on the full (ACE and ADE) models. As a first step of genetic model fitting analyses, the assumptions of mean and variance homogeneity within pairs and across zygosity groups have been tested in saturated models for each HCTI scale. The overall goodness of fit index of the full models (ACE or ADE) was calculated as the two times log-likelihood (-2LL).

\section{Results}

\subsection{Descriptive Statistics}

Prior to further analyses, the missing data patterns were analyzed. Overall missing rates were generally low, ranging from $0.6 \%$ to $2.6 \%$. Little's MCAR test (Little \& Rubin, 2002) indicated that the missing data occurred completely at random (all $p$ 's $>.05$ ), so that missing data could be computed using the expectation-maximization algorithm in SPSS for the subsequent analyses.

Descriptive statistics for the three HCTI full scales of Compliance, Aggression and Detachment, as well as the scale reliabilities, are depicted in Table 1 . All scales could be assumed as normally distributed given the guidelines of West, Finch, and Curran (1995) with values for Skewness of $|S| \leq 2$ and values for Kurtosis of $|K| \leq 7$. The three scale reliabilities ranged between $\alpha=.76$ and $\alpha=.82$, a finding which is consistent with the scale reliabilities for the normative sample (Coolidge, 1998).

\subsection{Intraclass Correlations}

Inspection of the ratio of MZ and DZ ICC (see Table 1), in which MZ twin similarity exceeded DZ similarity for all measures, indicated the contribution of genetic influences on the HCTI scales. DZ correlations were greater than half the MZ correlations for the Aggression and Detachment scales, while DZ correlations were less than half the MZ correlation for the Compliance scale. ACE models were therefore fitted for Aggression and Detachment scales, whereas an ADE model was assumed for the Compliance scale. However, the pattern of the ICC correlation for the Aggression scale also implied the presence of shared environmental effects. 
Table 1. Means (standard deviation), scale reliability and intraclass correlations of the three HCTI scales.

\begin{tabular}{|c|c|c|c|c|c|c|}
\hline \multirow[b]{2}{*}{ Measure } & \multicolumn{4}{|c|}{ Descriptive Statistics } & \multicolumn{2}{|c|}{ Intraclass correlation $(95 \% \mathrm{CI})$} \\
\hline & Mean (SD) & Skewness & Kurtosis & Cronbach’s Alpha & MZ & $\mathrm{DZ}$ \\
\hline Compliance & $51.10(7.85)$ & -.12 & .82 & .76 & $\begin{array}{c}.37 \\
(.13-.57)\end{array}$ & $\begin{array}{c}.05 \\
(-.35-.44)\end{array}$ \\
\hline Aggression & $40.71(7.54)$ & 1.04 & 2.38 & .82 & $\begin{array}{c}.59 \\
(.40-.74)\end{array}$ & $\begin{array}{c}.48 \\
(.10-.73)\end{array}$ \\
\hline Detachment & $35.42(7.12)$ & .88 & .67 & .78 & $\begin{array}{c}.46 \\
(.24-.64)\end{array}$ & $\begin{array}{c}.24 \\
(-.18-.57)\end{array}$ \\
\hline
\end{tabular}

Note: $N$ = 168 (60 MZ pairs, 24 DZ pairs); SD = standard deviation; ICC = Intraclass correlation; MZ = monozygotic twins; DZ = dizygotic twins; CI = Confidence interval.

\subsection{Model-Fitting Analysis}

To test for the assumptions of mean and variance homogeneity of the CTD, a fully saturated model was tested against a saturated model where means were equated within twin pairs and across zygosity for each of the HCTI scales. Subsequently, a model with additionally equated variances within pairs and across zygosity was tested. Akaike's information criterion (AIC; Akaike, 1987) was used to compare the fit of the models, whereby smaller AIC values indicate a better fit (Neale \& Maes, 2004). The model with equated means and variances was preferred according to the AIC for all three scales. Based on these results, the means and variances were equated between groups in the full genetic models. The fully saturated models provided the baseline for comparison of the genetic models for the three scales.

The results of the genetic model-fitting analyses are shown in Table 2. For the Compliance and Detachment scales, $36 \%$ and $46 \%$ of the observed phenotypic variance was explained by additive genetic influences, whereas the remaining variance was due to nonshared environmental effects. Shared environmental influences were not detected. As already was suggested by the inspection of the ICCs, interindividual differences in the Aggression scale were completely explained by environmental influences ( $57 \%$ shared and $43 \%$ nonshared). However, for the Aggression scale, the full ADE model fitted the data worse than the baseline model which means that the genetic model (i.e., the explanation of phenotypic variance by genetic and environmental influences given the assumed relatedness in these components of MZs compared to DZs) was not the most appropriate model to explain interindividual differences in this neurotic trend. The results of the genetic SEM modeling for Aggression should therefore only be carefully interpreted as tendencies. However, this missing heritability could also have been the result of the limited power of the twin sample, although curiously there was sufficient power to detect additive genetic effects in the Compliance and Detachment scales. An initial estimate of the genetic and environmental influences on a specific trait can also be derived directly from the ICCs. If the genetic influence was calculated with the Falconer formula for heritability (Falconer \& MacKay, 1996), which is $2\left(r_{M Z}-r_{D Z}\right)$, there would be an additive genetic effect of $22 \%$ for the Aggression scale.

\section{Discussion}

The goal of this study was to provide a test for two contrasting theoretical assumptions regarding the origins of Karen Horney's three neurotic trends. Based on explicit Horneyan theory, shared environmental influences would be expected as the major driving force of a manifestation of neurosis, whereas based on previous literature on the heritability of complex human traits, genetic as well as nonshared environmental influences would be expected as crucial for the explanation of phenotypic variance. To test these rival hypotheses, the genetic and environmental influences were examined on Karen Horney's three interpersonal neurotic trends in a young adult twin sample. Because this study is the first study to assess the heritability of her three trends, assumptions about the origins have been derived from behavioral genetic studies on theoretically related traits, namely personality disorders, coping styles, and the trait of neuroticism.

Consistent with previous empirical research, genetic influences were found for two of Horney's neurotic trends. Phenotypic variance in the compliance and detachment dimensions could be explained by additive genetic influences (36\% and $46 \%$, respectively), while the remaining variance was exclusively due to nonshared environmental influences. However, Horney's dimension of aggression did not show significant genetic influences: its phenotypic variance was explained by shared (57\%) and nonshared (43\%) environment. However, due 
Table 2. Model fitting results and standardized parameter estimates for the three HCTI scales.

\begin{tabular}{|c|c|c|c|c|c|c|c|}
\hline \multirow[b]{2}{*}{ Measure } & \multirow[b]{2}{*}{ Model } & \multirow[b]{2}{*}{$-2 L L$} & \multirow[b]{2}{*}{ df } & \multirow[b]{2}{*}{ AIC } & \multicolumn{3}{|c|}{ Parameter estimates (95\% CI) } \\
\hline & & & & & A & $\mathrm{C} / \mathrm{D}$ & $\mathrm{E}$ \\
\hline Compliance & $\mathrm{ADE}$ & 464.31 & 164 & 136.31 & $\begin{array}{c}.36 \\
(.00-.55)\end{array}$ & $\begin{array}{c}.00 \\
(.00-.38)\end{array}$ & $\begin{array}{c}.64 \\
(.00-.87)\end{array}$ \\
\hline Aggression & ACE & 445.97 & 164 & 117.97 & $\begin{array}{c}.00 \\
(.00-.60)\end{array}$ & $\begin{array}{c}.57 \\
(.00-.70)\end{array}$ & $\begin{array}{c}.43 \\
(.30-.59)\end{array}$ \\
\hline Detachment & ACE & 437.32 & 164 & 109.32 & $\begin{array}{c}.46 \\
(.00-.64)\end{array}$ & $\begin{array}{c}.00 \\
(.00-.45)\end{array}$ & $\begin{array}{c}.54 \\
(.36-.76)\end{array}$ \\
\hline
\end{tabular}

Note: $-2 \mathrm{LL}=-2$ times Log-likelihood of data; $\mathrm{df}=$ degrees of freedom; AIC = Akaike's information criterion; $\mathrm{A}=$ additive genetic variance; $\mathrm{C}=$ shared environmental variance; $\mathrm{D}=$ nonadditive genetic variance; $\mathrm{E}=$ nonshared environmental variance; $\mathrm{CI}=\mathrm{Confidence} \mathrm{Interval}$.

to the fact that the genetic model did fit the data worse than the saturated model and the assumed small genetic influences based on the ICCs, this result should be interpreted as preliminary. Nonetheless, the finding of environmental influences on aggression is consistent with studies on the heritability of antisocial personality disorder which is highly correlated with the Horney's aggressive neurotic trend (Coolidge et al., 2001), showing that antisocial behavior is heritable (32\% additive, 9\% nonadditive; see meta-analytic review by Rhee \& Waldman, 2002) but appears to be substantially influenced by shared (16\%) and nonshared environmental factors (43\%) (Rhee \& Waldman, 2002). Additionally, genetic influences on antisocial behavior seem to be more important in socioeconomically more advantaged environments, whereas shared environment was higher in socioeconomically less advantaged environments (Tuvblad, Grann, \& Lichtenstein, 2006).

The question now arises as to what extent the results of the present investigation are in accordance with Horney's claims that cultural factors in early childhood experiences (i.e., influences that would be expected to be shared among family members) largely or exclusively shape her major three neurotic trends. At least for her dimensions of compliance and detachment, the results of the behavior genetic modeling favor a genetic and nonshared environmental basis of these trends which appears mostly contradictory to Horney's theoretical assumptions. At this point, it is essential to take two additional aspects into account before evaluating her theory. First, as already mentioned, it may tentatively be assumed that Horney's real self was at least, in part, genetically predisposed (e.g., Grigorenko, 2011; Paris, 1999). Thus, the present results confirm a biological predisposition of an individuals' real self. Second, it is crucial to reconsider the meaning of the family environment as understood by Horney and to place this conceptualization into the broader context of behavioral genetic research.

Theories of socialization generally assume that the children's environments unfold within a family, which implicitly means a shared environment common to all members of a family (Plomin, 2011). The same understanding of the effect of environment applies for Horney's theory because she places a special emphasis on the importance of early interpersonal relationships within the nuclear family. For example, Horney (1945) clearly noted that particular pathogenic conditions in the early family environment could play a prominent role in the development of neurotic trends, as she stated that these early pathogenic factors might include: “...direct or indirect domination [by the parent of the child], indifference, erratic behavior, lack of respect for the child's needs, lack of real guidance, disparaging attitudes, too much admiration or the absence of it, lack of reliable warmth, having to take sides in parental disagreements, too much or too little responsibility, overprotection, isolation from other children, injustice, discrimination, unkept promises, hostile atmosphere, and so on and so on” (p. 41). Horney also suspected that it was unlikely that there was only a single pathogenic factor in the development in her neurotic trends, as she wrote that it was much more likely to be a combination of pathological conditions. With respect to these assumptions of specific early environmental circumstances, it could be assumed that pathological conditions are common to all children growing up in the same family, and therefore, they should be reflected in shared environmental rather than nonshared environmental influences.

One of the more remarkable findings of many behavioral genetic studies is that the salient environmental influences are not shared by family members, which means that those influences are rather perceived individually, and they are reflected as nonshared environmental influences (e.g., Plomin, 2011). The latter findings highlight the fact that individual perceptions of the environment can be an important source of non-shared experiences. A well-known example in this context is parenting style, which traditionally was assumed to be a shared factor for children growing up in the same family. However, it has been shown that while parents assume to treat their 
children equally, the children themselves perceive the parents' behavior in a fairly specific manner (sibling correlations of about $r=.20$; Reiss, Neiderhiser, Hetherington, \& Plomin, 2000). Another source of nonshared environmental variance lies in events shared by members of a family, such as divorce. For example, this shared event may be experienced differently by children in the same family, and thus would be reflected in a nonshared environmental influence (see Plomin, 2011).

In light of these general findings from behavioral genetic studies, the present results are consistent with Horney's expectations, as it might be assumed that the pathogenic family conditions are not necessarily perceived equally from all siblings in such a family. Additionally, Plomin (2011) highlighted the fact that "non-shared environment is not about events but rather is about effects on phenotypes" (p. 584). It is therefore reasonable that some siblings are at higher risk for these negative influences due to their own unique genetic makeup (even for identical twins), and their own unique attitudes, perceptions, and psychological responses to the same family conditions. Further, the key to understanding the effects of parental pathogenetic behavior may be that it is largely a function of the child's perceptions.

Moreover, it has come to be accepted that genetic factors are likely to play a role in response to environmental conditions, which has been described as gene-environment interaction in the behavioral genetic literature (e.g., Livesley \& Jang, 2008; Plomin et al., 2008). With respect to personality disorders, Kendler, Gardner, and Prescott (2003) noted that individual differences in personality, which are partly due to genetic influences, affect the way in which individuals perceive and structure the world around them. These differences should result in different experiences and reactions to stressful life events, and could affect the quality of interpersonal relationships, which in turn "feed back" on the individual and influence their risk for mental disorders (Kendler, Gardner, \& Prescott, 2003). An example of such a gene-environment interaction has been provided by a study of antisocial behavior (Caspi et al., 2002). Caspi and colleagues reported that only some children who were exposed to childhood maltreatment (specifically, erratic, coercive, and punitive parenting) develop antisocial behavior. They found that maltreated children with a genotype conferring high levels of the monoamine oxidase A (MAOA) gene were less likely to develop antisocial behavior (Caspi et al., 2002). To investigate the effect of gene-environment correlations and interactions, future studies are needed that specify and measure specific environmental characteristics and/or specific genes (Purcell, 2002).

Finally, caution is urged with respect to the interpretation of the substantial heritability estimates found for Horney's compliance and detachment dimensions as a high heritability does not imply immutability. Heritability is an estimate of the genetic influence on individual differences around a population mean (i.e., the population variance), rather than an estimate of the influences on the mean itself (Plomin et al., 2008).

There are several limitations of the present study: First, the sample size is small for a twin study, limiting the statistical power to detect significant genetic and environmental influences. This effect was mirrored in the large confidence intervals depicted in Table 2. As a consequence, the reported results should be interpreted as preliminary and studies with much larger samples are warranted. Further, the sample consisted predominantly of women (84\%), so it is not clear whether these results are generalizable to men as well.

Additionally, the pattern of results in the present study were not identical for all three dimensions, as shared and nonshared environmental influences appeared to be of greater relevance for Horney's aggression dimension. This finding is not easily understood, as all three dimensions should theoretically, as previously noted, have similar behavioral genetic patterns as primarily reactions to parental indifference, at least according to Horney. It is, of course, possible that the unusual pattern for the aggression dimensions was a statistical artifact. The behavior genetic model showed a significantly worse fit compared to the saturated phenotypic model which could be caused either by the small sample size and/or a misleadingly high DZ resemblance. It might be that the high DZ correlation in this scale is specific for the present sample which mainly consisted of young female adults (all same sex twin pairs). Although no sex differences were found in the preliminary ANOVAs, the sample size and the small number of male twin pairs (14 out of 84 pairs) was too small to capitalize any quantitative and qualitative sex differences. It also seems possible that the lack of heritability in the aggression dimension was an artifact of the disproportionately female sample. Perhaps, aggressive traits as defined by Horney (1945) are differently and differentially expressed in young adult men and women. It is also possible that although all three dimensions scales were in adequate range of scale reliability (.76 to .82), variance due to unreliability is included in the $\mathrm{E}$ influence which could result in an overestimation of $\mathrm{E}$ effects and consequently in an underestimation of $\mathrm{A}$ and $\mathrm{C}$ effects. However, why this occurred for only the aggression dimension remains uncertain.

Finally, the nonsignificance of shared environmental and nonadditive genetic influences does not inevitably 
imply that those influences are not present. As noted previously, the results could be due to a lack of statistical power of the CTD. For example, even a sample of 50,000 twins and relatives was not sufficient to show an effect of shared environment for the trait of neuroticism (Lake, Eaves, Maes, Heath, \& Martin, 2000). Moreover, as noted by Keller, Coventry, Heath, and Martin (2005), most studies using the CTD fail to detect nonadditive genetic effects. In contrast, Blonigen, Carlson, Krueger, and Patrick (2003) reported a significant genetic influence among psychopathic personality traits which were largely nonadditive in nature. Also, nonadditive genetic effects have been found for normal personality traits in extended behavioral genetic designs (e.g., twin-sibling studies, family studies, genetically sensitive multi-group designs) with large samples (e.g., Hahn, Spinath, Siedler, Wagner, Schupp, \& Kandler, 2012; Keller, Coventry, Heath, \& Martin, 2005).

Another important question that should be addressed in future studies is the development of neurotic trends throughout the lifespan, especially during the early years of childhood, to explore further the theoretically assumed development of neurotic trends. Here, genetically sensitive studies can be used to disentangle the causes of stability and change in these traits, and such studies could determine whether genetic influences are especially important to explain phenotypic variance in the early years (i.e., Horney’s real self) and whether nonshared environmental factors arise in especially sensitive periods for the development of neuroses.

\section{Conclusion}

Despite these limitations, it has been shown that at least two of Horney's three core neurotic trends, compliance and detachment, are substantially additively genetically influenced. However, this is not meant to imply that family experiences are unimportant, but rather that the relevant experiences that shape an individual's personality phenotype may be highly specific to each child in the family. The demonstrated importance of nonshared environmental influences suggests that identifying those specific environments that could contribute to the shaping of Horney's concept of a neurosis, as well as their correlation and interaction with individual characteristics, would be helpful with regard to possible interventions. However, to confirm these initial results and in order to understand the complex relations between genes and the environment over time, as well as to detect shared environmental and nonadditive genetic influences, a larger and more diverse sample (i.e., more groups of genetic relatedness) will be needed.

\section{References}

Akaike, H. (1987). Factor Analysis and AIC. Psychometrika, 52, 317-332. http://dx.doi.org/10.1007/BF02294359

American Psychiatric Association (1987). Diagnostic and Statistical Manual of Mental Disorders (3rd ed., rev). Washington DC: Author.

Blonigen, D. M., Carlson, S. R., Krueger, R. F., \& Patrick, C. J. (2003). A Twin Study of Self-Reported Psychopathic Personality Traits. Personality and Individual Differences, 35, 179-197. http://dx.doi.org/10.1016/S0191-8869(02)00184-8

Busjahn, A., Faulhaber, H. D., Freier, K., \& Luft, F. C. (1999). Genetic and Environmental Influences on Coping Styles: A Twin Study. Psychosomatic Medicine, 61, 469-475. http://dx.doi.org/10.1097/00006842-199907000-00011

Caspi, A., McClay, J., Moffitt, T. E., Mill, J., Martin, J., Craig, I. W., \& Poulton, R. (2002). Role of Genotype in the Cycle of Violence in Maltreated Children. Science (New York, N.Y.), 297, 851-854. http://dx.doi.org/10.1126/science.1072290

Coolidge, F. L. (1998). Horney-Coolidge Tridimensional Inventory: Manual. Colorado Springs, CO: Author.

Coolidge, F. L., Moor, C. J., Yamazaki, T. G., Stewart, S. E., \& Segal, D. L. (2001). On the Relationship between Karen Horney's Tripartite Neurotic Type Theory and Personality Disorder Features. Personality and Individual Differences, 30, 1387-1400. http://dx.doi.org/10.1016/S0191-8869(00)00120-3

Coolidge, F. L., Segal, D. L., Benight, C. C., \& Danielian, J. (2004). The Predictive Power of Horney’s Psychoanalytic Approach: An Empirical Study. The American Journal of Psychoanalysis, 64, 363-374. http://dx.doi.org/10.1007/s11231-004-4324-z

Coolidge, F. L., Segal, D. L., Estey, A. J., \& Neuzil, P. J. (2011). Preliminary Psychometric Properties of a Measure of Karen Horney's Tridimensional Theory in Children and Adolescents. Journal of Clinical Psychology, 67, 383-390. http://dx.doi.org/10.1002/jclp.20768

Coolidge, F. L., Thede, L. L., \& Jang, K. L. (2001). Heritability of Personality Disorders in Childhood: A Preliminary Investigation. Journal of Personality Disorders, 15, 33-40. http://dx.doi.org/10.1521/pedi.15.1.33.18645

Falconer, D. S., \& MacKay, T. F. (1996). Quantitative Genetics. Harlow: Prentice Hall.

Freud, S. (1913/2010). The Interpretation of Dreams (3rd ed.). Trans. by A. A. Brill. New York: The Macmillan Company, 
1913; Bartleby.com, 2010. www.bartleby.com/285/

Grigorenko, E. L. (2011). Introducing Neur-X, a Style of Being: The Transformation of a Concept. European Journal of Personality, 25, 273-274.

Hahn, E., Spinath, F. M., Siedler, T., Wagner, G. G., Schupp, J., \& Kandler, C. (2012). The Complexity of Personality: Advantages of a Genetically Sensitive Multi-Group Design. Behavior Genetics, 42, 221-233. http://dx.doi.org/10.1007/s10519-011-9493-y

Heszen-Niejodek, I. (1997). Coping Style and Its Role in Coping with Stressful Encounters. European Psychologist, 2, 342351. http://dx.doi.org/10.1027/1016-9040.2.4.342

Horney, K. (1945). Our Inner Conflicts. New York: W. W. Norton \& Co., Inc.

Horney, K. (1950). Neurosis and Human Growth: The Struggle towards Self-Realization. New York: W. W. Norton \& Co., Inc.

Jang, K. L., Thordarson, D. S., Stein, M. B., Cohan, S. L., \& Taylor, S. (2007). Coping Styles and Personality: A Biometric Analysis. Anxiety, Stress \& Coping: An International Journal, 20, 17-24. http://dx.doi.org/10.1080/10615800601170516

Johnson, A. M., Vernon, P. A., \& Feiler, A. R. (2008). Behavioral Genetic Studies of Personality: An Introduction and Review of the Results of 50+ Years of Research. In The SAGE Handbook of Personality Theory and Assessment: Volume 1, Personality Theories and Models (pp. 145-173). London: Sage Publications.

Johnson, W., Turkheimer, E., Gottesman, I. I., \& Bouchard Jr., T. J. (2009). Beyond Heritability: Twin Studies in Behavioral Research. Current Directions in Psychological Science, 18, 217-220. http://dx.doi.org/10.1111/j.1467-8721.2009.01639.x

Keller, M. C., Coventry, W. L., Heath, A. C., \& Martin, N. G. (2005). Widespread Evidence for Non-Additive Genetic Variation in Cloninger's and Eysenck's Personality Dimensions Using a Twin plus Sibling Design. Behavior Genetics, 35, 707-721. http://dx.doi.org/10.1007/s10519-005-6041-7

Kendler, K. S., Gardner, C. O., \& Prescott, C. A. (2003). Personality and the Experience of Environmental Adversity. Psychological Medicine, 33, 1193-1202. http://dx.doi.org/10.1017/S0033291703008298

Kendler, K. S., Kessler, R. C., Heath, A. C., Neale, M. C., \& Eaves, L. J. (1991). Coping: A Genetic Epidemiological Investigation. Psychological Medicine, 21, 337-346. http://dx.doi.org/10.1017/S0033291700020444

Kozak, B., Strelau, J., \& Miles, J. N. V. (2005). Genetic Determinants of Individual Differences in Coping Style. Anxiety, Stress \& Coping: An International Journal, 18, 1-15. http://dx.doi.org/10.1080/10615800500040844

Lake, R. I., Eaves, L. J., Maes, H. H., Heath, A. C., \& Martin, N. G. (2000). Further Evidence against the Environmental Transmission of Individual Differences in Neuroticism from a Collaborative Study of 45,850 Twins and Relatives on Two Continents. Behavior Genetics, 30, 223-233. http://dx.doi.org/10.1023/A:1001918408984

Little, R. J. A., \& Rubin, D. B. (2002). Statistical Analysis with Missing Data. Hoboken, NJ: John Wiley \& Sons. http://dx.doi.org/10.1002/9781119013563

Livesley, W. J., \& Jang, K. L. (2008). The Behavioral Genetics of Personality Disorder. Annual Review of Clinical Psychology, 4, 247-274. http://dx.doi.org/10.1146/annurev.clinpsy.4.022007.141203

McCrae, R. R., \& Costa Jr., P. T. (1999). A Five-Factor Theory of Personality. In L. A. Pervin, \& O. P. John (Eds.), Handbook of Personality Psychology (pp. 139-153). New York: Guilford.

McGue, M., \& Bouchard, T. J. (1984). Adjustment of Twin Data for the Effects of Age and Sex. Behavior Genetics, 14, 325343. http://dx.doi.org/10.1007/BF01080045

Neale, M. C., \& Maes, H. H. (2004). Methodology for Genetic Studies of Twins and Families. Dordrecht: Kluwer Academics.

Neale, M. C., Boker, S. M., Xie, G., \& Maes, H. (2003). Mx: Statistical Modeling. Richmond, VA: Virginia Commonwealth University Medical School, Department of Psychiatry.

Neale, M. C., Eaves, L. J., \& Kendler, K. S. (1994). The Power of the Classical Twin Study to Resolve Variation in Threshold Traits. Behavior Genetics, 24, 239-258. http://dx.doi.org/10.1007/BF01067191

Nichols, R. C., \& Bilbro Jr., W. C. (1966). The Diagnosis of Twin Zygosity. Human Heredity, 16, 265-275. http://dx.doi.org/10.1159/000151973

Ozaki, K., Toyoda, H., Iwama, N., Kubo, S., \& Ando, J. (2011). Using Non-Normal SEM to Resolve the ACDE Model in the Classical Twin Design. Behavior Genetics, 41, 329-339. http://dx.doi.org/10.1007/s10519-010-9386-5

Paris, B. J. (1994). Karen Horney: A Psychoanalyst's Search for Self-Understanding. New Haven, CT: Yale University Press.

Paris, B. J. (1999). Karen Horney’s Vision of Self. American Journal of Psychoanalysis, 59, 157-166. http://dx.doi.org/10.1023/A:1022003629731

Plomin, R. (2011). Commentary: Why Are Children in the Same Family So Different? Non-Shared Environment Three 
Decades Later. International Journal of Epidemiology, 40, 582-592. http://dx.doi.org/10.1093/ije/dyq144

Plomin, R., DeFries, J. C., McClearn, G. E., \& McGuffin, P. (2008). Behavioral Genetics. New York: Worth Publishers.

Polderman, T. J., Benyamin, B., de Leeuw, C. A., Sullivan, P. F., van Bochoven, A., Visscher, P. M., \& Posthuma, D. (2015). Meta-Analysis of the Heritability of Human Traits Based on Fifty Years of twin studies. Nature Genetics, 47, 702-709. http://dx.doi.org/10.1038/ng.3285

Purcell, S. (2002). Variance Components Models for Gene-Environment Interaction in Twin Analysis. Twin Research, 5, 554-571. http://dx.doi.org/10.1375/136905202762342026

Reichborn-Kjennerud, T. (2010). The Genetic Epidemiology of Personality Disorders. Dialogues in Clinical Neuroscience, 12, 103-114.

Reiss, D., Neiderhiser, J., Hetherington, E. M., \& Plomin, R. (2000). The Relationship Code: Deciphering Genetic and Social Patterns in Adolescent Development. Cambridge, MA: Harvard University Press.

Rhea, S. A., Gross, A. A., Haberstick, B. C., \& Corley, R. P. (2006). Colorado Twin Registry. Twin Research and Human Genetics, 9, 941-949. http://dx.doi.org/10.1375/twin.9.6.941

Rhee, S. H., \& Waldman, I. D. (2002). Genetic and Environmental Influences on Antisocial Behavior: A Meta-Analysis of Twin and Adoption Studies. Psychological Bulletin, 128, 490-529. http://dx.doi.org/10.1037/0033-2909.128.3.490

Rijsdijk, F. V., \& Sham, P. C. (2002). Analytic Approaches to Twin Data Using Structural Equation Models. Briefings in Bioinformatics, 3, 119-133. http://dx.doi.org/10.1093/bib/3.2.119

Shrout, P. E., \& Fleiss, J. L. (1979). Intraclass Correlations: Uses in Assessing Rater Reliability. Psychological Bulletin, 86, 420-428. http://dx.doi.org/10.1037/0033-2909.86.2.420

Sullivan, P. F., \& Eaves, L. J. (2002). Evaluation of Analyses of Univariate Discrete Twin Data. Behavior Genetics, 32, 221227. http://dx.doi.org/10.1023/A:1016025229858

Torgersen, S. (2009). The Nature (And Nurture) of Personality Disorders. Scandinavian Journal of Psychology, 50, 624-632. http://dx.doi.org/10.1111/j.1467-9450.2009.00788.x

Turkheimer, E. (2000). Three Laws of Behavior Genetics and What They Mean. Current Directions in Psychological Science, 9, 160-164. http://dx.doi.org/10.1111/1467-8721.00084

Tuvblad, C., Grann, M., \& Lichtenstein, P. (2006). Heritability for Adolescent Antisocial Behavior Differs with Socioeconomic Status: Gene-Environment Interaction. Journal of Child Psychology and Psychiatry, 47, 734-743. http://dx.doi.org/10.1111/j.1469-7610.2005.01552.x

Visscher, P. M., Gordon, S., \& Neale, M. C. (2008). Power of the Classical Twin Design Revisited: II Detection of Common Environmental Variance. Twin Research and Human Genetics, 11, 48-54. http://dx.doi.org/10.1375/twin.11.1.48

Watson, D., Clark, L. A., \& Harkness, A. R. (1994). Structures of Personality and Their Relevance to Psychopathology. Journal of Abnormal Psychology, 103, 18-31. http://dx.doi.org/10.1037/0021-843X.103.1.18

West, S. G., Finch, J. F., \& Curran, P. J. (1995). Structural Equation Models with Nonnormal Variables: Problems and Remedies. In R. H. Hoyle (Ed.), Structural Equation Modeling: Concepts, Issues, and Applications (pp. 56-75). Thousand Oaks, CA: Sage Publications. 